University of Nebraska - Lincoln

DigitalCommons@University of Nebraska - Lincoln

Educational Psychology Papers and

Publications

Educational Psychology, Department of

January 1995

Parent Training in Interactive Book Reading: An Investigation of Its Effects with Families at Risk

Anne Taverne

Salt Lake City Schools

Susan M. Sheridan

University of Nebraska-Lincoln, ssheridan2@unl.edu

Follow this and additional works at: https://digitalcommons.unl.edu/edpsychpapers

Part of the Educational Psychology Commons

Taverne, Anne and Sheridan, Susan M., "Parent Training in Interactive Book Reading: An Investigation of Its Effects with Families at Risk" (1995). Educational Psychology Papers and Publications. 71.

https://digitalcommons.unl.edu/edpsychpapers/71

This Article is brought to you for free and open access by the Educational Psychology, Department of at DigitalCommons@University of Nebraska - Lincoln. It has been accepted for inclusion in Educational Psychology Papers and Publications by an authorized administrator of DigitalCommons@University of Nebraska - Lincoln. 


\title{
Parent Training in Interactive Book Reading: An Investigation of Its Effects with Families at Risk
}

\author{
Anne Taverne \\ Salt Lake City Schools \\ Susan M. Sheridan* \\ University of Utah \\ *Corresponding author
}

\begin{abstract}
This study investigated the efficacy of a parent training intervention on increasing the duration, frequency and quality of interactive book reading between six parents and their children. Dependent measures included self-reports of frequency and duration of parent-child interactive reading, coding of transcripts for reading quality, children's pre-post PPVT-R performance, consumer satisfaction questionnaires, and assessment of treatment integrity. During treatment, five of six subjects improved in reading regularity and duration. Likewise, all subjects demonstrated improvements in the quality of interactive book reading with their children. Children's PPVT-R performance also increased upon post-testing. Consumer satisfaction and treatment integrity were favorable. Study strengths and limitations, implications for school psychological practice, and future research questions are addressed.
\end{abstract}

Recent demographic changes in the United States have produced increased cultural and linguistic diversity in students attending public schools in the United States. Barona, Santos de Barona, Flores, and Gutierrez (1990) reported that 21\% of the nation's population belong to ethnic minority groups, including AfricanAmerican, Hispanic-American, and Asian-American. Poor academic results are not specific to any one group, nor can it be assumed that all students with diverse linguistic and cultural backgrounds will do poorly in school. However, there is evidence that many of our nation's minority students can be described as educationally at-risk.

The term "at risk" is often used to describe students who experience academic failure (Cooper \& Speece, 1990), drop out of school (Wehlage, Rutter, \& Turnbaugh, 1987), or have limited English language skills (Duran, 1989; Fradd \& Weismantel, 1989). Natriello, McDill, and Pallas (1990) characterized students at risk as having (a) poverty in the household; (b) minority/racial group identity; (c) parental educational failure; (d) a single parent; and (e) a non-English lan- 
guage background. All of these indicators are correlated with poor performance in school. In general, the greater the number of risk factors present, the greater the probability of disadvantage (Davis, 1991).

Most discussions on educational disadvantage focus on students from minority or impoverished backgrounds. These students historically have been considered at risk due to social class, race, ethnic origin, or poverty and may come to school unprepared to learn effectively (Passow, 1970; Welch \& Sheridan, 1995). Barona et al. (1990) reported drop out rates for Hispanic-Americans reached 50 percent in some communities. Among students who graduate, below-grade-level reading has been found (Clark, 1988). While there is a dire need to provide services to students and families presenting risk factors, research-based service delivery options for school psychologists working with such families are generally lacking.

A recent study conducted in a Western urban school district compared standardized group achievement test results for students of different ethnic backgrounds. Students of Hispanic-American background composed 12 percent of the school population and were the district's largest minority group. Scores of this group were on the average one standard deviation below those of their Anglo-American peers (P. Osegura, personal communication, 1990). Dropout rates for Hispanic-Americans approached 40 percent compared to approximately 20 percent for all students in the district.

In a summary of research on minority groups conducted by the National Education Association, Edwards (1991) reported that all groups wanted schools to recognize and "reflect their values and way of life" (p. 223), and desired some control over their children's education. Common barriers to minority parent participation in the public schools include poor literacy skills, language deficits, cultural distance from school and community, unwillingness or inability to attend meetings, and inability to implement suggestions. An important way that public schools have attempted to increase minority parent participation and attenuate the impact of poverty has been through improving the literacy skills of minority families (Edwards, 1991).

\section{Literacy Training with Educationally At-Risk Families}

A common focus in interventions research for the educationally at-risk is children's reading and literacy skills (Becher, 1985; Edwards, 1991; Morrow, 1983; Pellegrini, Perlmutter, Galda, \& Brody, 1990; Shields \& Dupree, 1983). Teale and Sulzby (1989) reviewed a number of studies and concluded that child engagement in activities such as print awareness, self-monitoring when recalling a story (i.e., metacognition), and modeling of adult behaviors with printed materials were important contributors to emergent literacy. Parent-child interactions appear to be a major stimulus to the development of early reading skills (Teale, Hieber, \& Chittenden, 1987). Supportive behavioral accommodations on the part of adults, such as matching their behaviors and verbalizations to their child's abilities, have been translated into strategies of interactive teaching that 
stress the reciprocal and interpersonal nature of learning (Hall, 1989; Rice, 1989; Snow, 1983). Naturalistic teaching strategies were found to be most supportive with children who have limited language opportunities (Paget \& Galant, 1991).

Several important studies have reported positive outcomes for minority home reading practices, especially between parents and young school children (e.g., Huang, 1992; Tizard, Schofield, \& Hewison, 1982). In a study of low SES African-American families, Shields and Dupree (1983) found that parents of good readers gave praise for student school success, bought books relevant to children's interests, and also assigned children home responsibilities. Morrow (1983) found that parents of kindergarten students with high interest in literacy activities read more, watched less television, and placed books in more rooms in the house, including the kitchen and children's bedrooms.

These findings are supported by a study undertaken by Edwards and Panofsky (1988). The researchers exposed one group of Head Start mothers to motivational presentations and discussions on the importance of reading. A second group engaged in book-reading training, including modeling. Parents in the modeling group were found to demonstrate increased initiative and use of questions and comments. Both mothers and children improved in use of referential language. Although these studies are encouraging, they lack precision on the nature of interaction between school staff and parents as well as procedures for training parents in home reading. Each study demonstrates that training in-home reading is acceptable to low SES or minority parents; however, the specific training procedures are not identified.

\section{Parent Training}

According to Dembo, Sweitzer, and Lauritzen (1985), "Parent training... is defined as a process that includes at least one component, teaching specific skills" (p. 156). Some parent-training models are broad programs that attempt to train general parenting skills, such as effective discipline or compliance. Others are specific programs designed to remediate certain behavioral problems (such as noncompliance), or develop discrete skills at behavioral management (such as the use of positive reinforcement or timeout).

Three theoretical orientations of parent-training are common in the professional literature, including humanistic, Adlerian, and behavioral (see Fine, 1990 and Kramer, 1990 for reviews). Of these models, behavioral parent-training programs have received the greatest amount of research attention, and generally have yielded promising results (Sheridan, 1993). In a meta-analytic analysis of the parent education and training literature, Medway (1989) concluded that the behavioral model had the greatest effects on child behavior measures. Furthermore, Dembo et al. (1985) suggested that behavioral parent-training studies have fewer methodological flaws and utilize a larger number of outcome variables. Behavioral parent-training programs (e.g., Barkley, 1990; Forehand \& McMahon, 1981; Webster-Stratton, 1989) share common features that emphasize the 
acquisition and performance of specific behavioral management skills. Parenttrainers typically use methods such as discussion, modeling, role-playing, guided practice, and homework assignments (Kramer, 1990).

Parent-training practices with minority families at risk present unique challenges. Low-SES parents have been found to be less likely to enroll, attend, and finish group sessions than middle class parents (Fine, 1989; McMahon \& Forehand, 1984). Even if the parent does not drop out of treatment, certain characteristics (including single-parent and low socioeconomic status) may reduce the effectiveness of parent-training (Bernal, 1984). Perhaps certain requirements of behavioral parent-training programs, such as homework, monitoring of behavior, and attendance at meetings are not family priorities, and may thus conflict with other realities of their lives. Likewise, it has been suggested that certain features of traditional behavioral parent-training such as instruction in the contingencies necessary for behavioral change, may conflict with cultural traditions valued by some groups (Huang \& Gibbs, 1992). Therefore, it is necessary to develop parent-based interventions that are acceptable and appropriate for minority and lowSES families. At present, there are no known parent-training studies that have investigated instruction of interactive book reading for families at risk.

\section{Purpose of the Study}

The current study falls within a broad context of developing validated and replicable practices for educators who provide services to diverse populations in public school settings. The specific intervention goal was to increase interactive book reading in low-literacy homes. The primary research questions included: (a) Will parent-training in interactive book reading techniques result in increased quantity and quality of reading interactions between parent and child? (b) Will target children's measures of receptive vocabulary increase following the practice of interactive book reading? and (c) Will parents consider skills training acceptable and effective?

\section{METHODS}

\section{Subjects}

Subjects in this study were six mother/preschool/child dyads who were recruited from low-income, urban neighborhood schools. All dyads were enrolled in the school district's Even Start, an early intervention and literacy program designed for educationally at-risk families. A defining characteristic of Even Start families was that parents had not completed a North American high school degree. Norm-referenced parent reading ability was assessed using the Test of Adult Basic Education (TABE). Typical reading skill was approximately fourth grade.

Subjects who dropped out of the subject pool included two single parents living with extended families (one Hispanic-American and one Native-American) and one Hispanic-American mother who separated from her husband during the intervention period. The two Hispanic-Americans left the study at the implemen- 
tation of baseline data collection and the Native-American mother, who did not have an established home, left the study after week three of skills training. All subjects leaving the study gave lack of time or conflicting family responsibilities as their reason.

The six mothers completing the study ranged in age from 21 to 39 years (M $=28, S D=6.1$ ). All mothers except one were married, with spouses living in the home. Three spouses were reported to be employed full-time and two were reported to be employed part-time. Two families were composed of first-generation Mexican immigrants. Three mothers grew up in the western United States in homes where Spanish was spoken. One mother spoke only English. Except for one parent who reported some college training in Mexico, parents stopped attending school between grades nine and eleven. Parents reported lack of education, unavailability of reading materials, child management problems, and conflicts with other work responsibilities as reasons for not reading with their child.

Parents initially were informed of the reading program by letter, including a self-addressed stamped envelope for a return reply. This did not prove to be an effective means of contacting parents, as only one parent responded to this notification. Subsequently, the investigator made direct telephone calls to their homes. Also, parents with excessive emotional, behavioral, or learning difficulties were ruled out by the investigator and Even Start site coordinators using available information (e.g., family histories) and professional judgment.

Children in the present study included five females and one male. Target children ranged in age from 3-4 to 5-5 years $(M=4.6, S D=8.2$ months). The Kaufman Brief Intelligence Test (K-BIT) (Kaufman \& Kaufman, 1990) was administered to rule out learning difficulties and borderline intelligence that would preclude participation. Children obtained K-BIT composite scores ranging from 79 (below average) to 113 (above average) $(M=97.8$; average, $S D=10.5)$. Because of the Hispanic-American background common to five of the six parents, the nonverbal matrices subtest was considered the best nonbiased ability measure. Scores on matrices ranged from 81 (low average) to 121 (superior) $(M=$ 102.2 , average; $S D=11.8$ ). Vocabulary scores ranged from 80 (low average) to 105 (average) $(\mathrm{M}=93.8$, average; $S D=8.5)$.

\section{Procedures}

All aspects of the intervention were carried out by the senior author/investigator who has practiced in public schools as a school psychologist for 14 years. Home visits were conducted at the beginning and end of the study, and skills training occurred in two public school settings. A preschool assistant was employed to supervise day-care while parents met with the investigator.

\section{Materials}

Reading $\log$. The log was a simple one-page form representing a seven-day week, with weekdays divided into morning and afternoon times. Each parent completed one log weekly, writing down the inclusive dates and reading times. 
Parents tallied reading minutes and compared performance with the preceding weeks at meetings with the investigator.

Reading Summary. The summary was a 9-item instrument that required parents to rate on a 4-point scale their perceptions about their own book reading with their child. Items corresponded with training goals and the form served as a check on treatment integrity. Parents completed a summary for each reading during the first two weeks and at least once weekly thereafter. Summaries were turned in to the investigator at the end of the week.

Books. Five books were provided to parents (i.e., one for each week of treatment). The books were 20 to 30 pages in length, and were chosen by the senior investigator. They were chosen with a concern that topics be varied but identifiable to those of different cultural backgrounds, that the language be realistic and uncomplicated, and that illustrations provide opportunities for naming and discussion. Particular attention was paid to the inclusion of pictures that allowed parent-child interaction. Reading skills required for the books were estimated to be fourth-grade or below.

Audio and visual demonstrations. There was one audio and one visual teaching component introduced during skills training. During week 1, parents listened to and read along with a commercially prepared tape recording (Wright Group, 1990) of a teacher demonstrating interactive book reading techniques.

Toward the end of treatment (week 4 or week 5), parents observed a training videotape developed by the investigator. The videotape depicted a mother and her six-year-old, Asian-Indian child engaged in interactive book reading. Subjects observed the mother and her daughter reading and discussing 2 stories to which they were previously exposed. On the tape, the mother modeled various interactive book reading skills, including awareness of book structure and print, and vocabulary development. Subtle behavior management skills were also modeled, such as ignoring and redirecting.

\section{Independent Variables}

Interactive Book Reading. Interactive book reading was defined as a parentchild activity during which a parent (a) examined a storybook and pointed out its main parts, (b) labeled and discussed picture content, (c) read aloud the story to the child, and (d) paused to question the child about his or her understanding. Likewise, the parent might engage the child in discussion about experiences the book brought to mind or possibly school-related concepts such as colors, shapes, and numbers. At each reading of a book, the parent was to teach identification of book components (author, title, and story theme) and to encourage child identification of print characteristics. Specific target behaviors were developed based upon descriptive studies of preschool children's emergent literacy skills (Sulzby, 1985; Teale et al., 1987; Teale \& Sulzby, 1989).

The goals of training were translated into a nine-code system for the analysis of target behavior (verbal statements requiring interaction between parent, child, 
and text) occurring during reading. Table 1 lists and defines the parent and child codes. Codes 1 to 5 categorized parent statements, whereas Codes 6 to 9 dealt with child statements. Statements that did not fit the coding scheme (such as arbitrary comments or unrelated commands) were coded with O for "other." Codes were not given to parents' rote reading of book text.

The coding scheme required that a rater assign one code to each statement unit. A statement unit was defined as a parent's or child's spontaneous speaking turn occurring during tape-recorded, interactive book reading. For example, a parent statement followed by a child response would be an occasion for two codes; one assigned to the parent's statement and one assigned to the child's. Coded parent-child exchanges were spontaneous in nature, and statement units did not necessarily assume the form of complete sentences. When one speaking turn yielded two possible codes, the code with the highest numerical value was assigned.

Parent-Training. Parent-training of interactive book reading skills occurred over a period of seven weeks in both individual and small group sessions between the investigator and parent subjects. An initial home visit was conducted to review the study procedures with parents, obtain information about existing and past family reading practices, set goals, and review data collection procedures. Baseline data collection using logs and audiotape recordings ensued at this point.

Seven to 10 days following home visits, individual meetings occurred between the investigator and parents to review the logs and develop a plan for setting up a regular schedule of interactive book reading at home. Following individual meetings, five weekly small group skills training sessions lasting approximately 60 minutes were held with one to three parents. Although parents were reminded of upcoming appointments by telephone, each parent missed approximately one skills training session.

The skills training sessions consisted of general discussion, modeling, roleplaying, and performance feedback. The usual sequence of activities included a review of weekly logs, introduction and distribution of the book for the week, and demonstration of reading techniques applicable to the book at hand. A roleplay immediately followed, during which the parent acted the part of the reader and received coaching and feedback (from the investigator or from a parent partner) on their use of techniques.

\section{Dependent Variables}

Transcript Reviews. Reviews of parents' interactive book reading were conducted with the use of weekly tape recordings. Specifically, parents audiotaped reading sessions with their child during baseline, treatment and follow-up conditions. Unfortunately, due to subject resistance to extended baseline conditions, only one week of baseline data (i.e., one data point) is available. Audiotapes were transcribed and coded by two graduate student raters trained by the investigator (see coding scheme in Table 1). Interrater reliability was established using percentage agreement and kappa procedures. Interrater agreement for $40 \%$ 
Table 1. Interactive Book Reading Codes

Behavior Codes

Definition

1. Labeling

Parent assists child in developing new use of vocabulary words.

Parent says or provides a label for (1) an object, (2) a person, (3) a place, (4) a qualifier, or (5) an action word.

Parent asks a why, what, where, or how question.

Parent says or provides a word or phrase close in meaning to another word already used.

2. Verbal Expression

Parent models verbal fluency. Parent expands upon child's utterance, providing a more complete sentence structure.

Parent validates child's utterance by repeating the child's word or saying "yes,," "oh,," or "uh huh."

Parent comments on the story as she reads.

3. Prior Knowledge

4. Book Structure

5. Print Awareness

6. Vocabulary Development

7. Verbal Expression

8. Book Structure

9. Print Awareness

10. Other
Parent questions or comments so as to encourage child to recall a previous experience or prior knowledge.

Parent encourages child to make judgments about the story.

Parent helps child to recall a previous experience related to the story.

Parent assists child in developing awareness of the book's physical organization or story narrative.

Parent calls attention to parts of the book such as author, illustrator, and cover pages.

Parent identifies cause and effect relations or chains of events that relate to the main narrative.

Parent leads a summary of story events. (Tangential or merely descriptive comments should be ruled out.)

Parent encourages child's retelling of parts of the story.

Parent encourages child's attending to print characteristics of the book.

Child labels for the first time in the reading session a noun, descriptor, or descriptive verb.

Child asks a what, where, or how question.

Child repeats all or part of parent expansion, making at least a three word utterance.

Child uses language to recall memorized story fragments, to relate her or his prior experience, or to express new ideas.

Child practices concepts learned or asks for a clarification of a concept.

Child responds to parent's prompt with a "yes" or a "no" answer.

Child identifies a cause and effect sequence associated with the story narrative.

Child recalls the story name, its author or illustrator, or notes cover characteristics.

Child notes parts of the narrative such as what comes first, second, and last.

Child recalls a common refrain.

Child attends to aspects of the book's print.

Child asks about or reads a number, word, letter, or letter sound.

This code includes statements that are not coded according to the other nine criteria. An example is "Take your fingers out of your mouth." 
of randomly selected transcripts was .87. Kappa was computed, yielding coefficients from .33 to 1.0 across the nine codes.

Receptive Vocabulary. The Peabody Picture Vocabulary Test-Revised (PPVTR) was administered before and following intervention for the purpose of determining levels of children's receptive vocabulary. Approximately six months elapsed between pretest and posttest administrations. Comparison scores existed for three of the six children for PPVT-Rs administered by Even Start staff approximately six months before the pretest measure.

Self-Reports. Minutes read per day and days read per week were recorded by subjects on reading logs across the three conditions (baseline, treatment, and follow-up).

Treatment Acceptability. The Behavior Intervention Rating Scale (BIRS) (Von Brock \& Elliott, 1987) was administered to determine the acceptability of the intervention. Mothers completed the BIRS with the assistance of the investigator at the follow-up time.

Treatment Integrity. Parents' demonstration of interactive book reading techniques was assessed with both the reading summaries and expert reviews of reading transcripts.

\section{Design and Data Analysis}

An A-B follow-up with replication design was used (Harris \& Jenson, 1985; Tawney \& Gast, 1984). All parent-child dyads received the same intervention, with staggered starting points beginning from one to five weeks after subject identification. For each subject, data collection included one week of baseline, five weeks of treatment, and one week of follow-up.

Self-report (i.e., log) data were analyzed visually for evidence of immediacy of change and change in trend across three intervention phases. Plotted data points were analyzed for evidence of stability within and overlap between conditions. Changes in the level and slope between baseline and treatment conditions were also analyzed statistically using interrupted time series analysis procedures (DMITSA) (Crosbie \& Sharpley, 1991). DMITSA uses matrix algebra to determine autocorrelation values and changes in level and slope that best fit the data. Autocorrelation is then removed so that statistical tests can be employed to determine whether a significant change is evidenced between baseline and treatment phases. DMITSA provides an F-value and indicates the probability that such a value would occur by chance.

\section{RESULTS}

\section{Self-Reports: Reading Log}

Reading log data depicting days per week and minutes per day each subject engaged in interactive-book reading are presented in Figure 1. Averages across conditions and subjects are in Table 2. 
Table 2. Weekly Means for Number of Minutes Read and Number of Reading Days Across Three Experimental Conditions

\begin{tabular}{|c|c|c|c|c|c|c|}
\hline \multirow[b]{2}{*}{ Subject } & \multicolumn{2}{|c|}{ Baseline } & \multicolumn{2}{|c|}{ Treatment } & \multicolumn{2}{|c|}{ Follow up } \\
\hline & Minutes & Days & Minutes & Days & Minutes & Days \\
\hline 1 & 30 & 1 & 135 & 3.3 & 60 & 2 \\
\hline 2 & 0 & 0 & 80 & 4.4 & 115 & 5 \\
\hline 3 & 30 & 2 & 54 & 2.3 & 36 & 2 \\
\hline 4 & 50 & 3 & 24 & 1.6 & 60 & 3 \\
\hline 5 & 0 & 0 & 137 & 4.4 & 225 & 6 \\
\hline 6 & 40 & 3 & 43 & 4.6 & 35 & 6 \\
\hline Total & 150 & 9 & 473 & 20.6 & 531 & 24 \\
\hline$M$ & 25 & 1.5 & 79 & 3.4 & 88.5 & 4 \\
\hline$S D$ & 18.9 & 1.3 & 43.7 & 1.4 & 66.6 & 1.7 \\
\hline
\end{tabular}

As can be seen in Table 2, five of six subjects (or 83\%) reported treatment gains in both number of days read and number of minutes engaged in interactive book reading. The average increase across subjects was 1.93 days per week and 54 minutes per week. Based on time-series analysis (i.e., DMITSA), four of six subjects exhibited significant changes in level $(p<.05)$ with the implementation of treatment (Subjects 2, 3, 4 and 5). Only Subject 4 demonstrated a decrease in number of days and minutes read. Furthermore, this same subject demonstrated a significant change $(p<.01)$ in slope between baseline and treatment, and this change was in the negative direction. Four of six subjects (Subjects 2, 3, 5 and 6) demonstrated a treatment effect rather immediately with the onset of treatment.

Compared to baseline, all subjects reported reading the same number or more days per week at follow-up ( $\mathrm{M}$ increase $=2.5$ days). Only one subject (Subject 6) reported a decrease in minutes read per week between baseline and follow-up $(\mathrm{M}$ increase $=63.5$ minutes). Likewise, four parents (Subjects 1, 2, 5, and 6) reported maintaining or improving treatment gains into follow up for number of days read ( $\mathrm{M}$ increase $=.57$ days), and three parents reported increases in minutes read per week from treatment to follow-up conditions ( $\mathrm{M}$ increase $=9.67$ minutes). It should be noted that with the exception of Subject 1, who set a goal of reading to her child five days per week, all subjects met and maintained their stated treatment goals.

\section{Interactive Book Reading Transcriptions}

Individual dyads' acquisition of interactive reading skills, expressed as the number of coded statements evident in interactive book reading transcripts, are summarized in Table 3 and Figure 2. Because of the nature of skill attainment, an unstable, upward trend was expected in subjects' data. Unfortunately only one baseline data point is available for all subjects, making the use of time-series analysis procedures (i.e., DMITSA) inappropriate.

Data for the six dyads indicated increases in the number of meaningful interactions between parent and child during treatment compared to baseline per- 
Table 3. Number of Statement Units in Dyads' Transcriptions for Three Conditions and the Final Treatment Week

\begin{tabular}{lcccc}
\hline & \multicolumn{4}{c}{ Treatment } \\
\cline { 2 - 5 } Subject & Baseline & Treatment $M$ & (final week) & Follow-up \\
\hline 1 & 6 & 106 & 96 & 96 \\
2 & 0 & 144 & 275 & 225 \\
3 & 93 & 303 & 611 & 313 \\
4 & 3 & 109 & 263 & 20 \\
5 & 0 & 60 & 93 & 22 \\
6 & 0 & 116 & 58 & 58 \\
Total & 105 & 839 & 1396 & 774 \\
$M$ & 18 & 140 & 233 & 129 \\
$S D$ & 35.3 & 77 & 189.1 & 116 \\
Range & $0-93$ & $60-303$ & $58-611$ & $20-313$ \\
\hline
\end{tabular}

formance. The mean increase across subjects from baseline to treatment conditions was 122 codable interactions. Three of the six dyads (50\%) maintained treatment gains at follow-up. Three other dyads made gains over baseline and demonstrated maintenance of some, but not all, gains at follow-up.

\section{Receptive Language}

Results of the two administrations of the PPVT-R are summarized in Table 4. In addition, available Even Start data from the autumn preceding the intervention are included for three children. Data indicate an increase in the acquisition of receptive vocabulary for each child involved in the reading program. The average score for the six children was 84.8 prior to treatment (range $=73$ to 92 ). This

Table 4. Peabody Picture Vocabulary Test-Revised Standard Scores for Children Before and After Parent Training

\begin{tabular}{lcccc}
\hline Subject & $\begin{array}{c}\text { Pretest } \\
\text { Autumn 1990 }\end{array}$ & $\begin{array}{c}\text { Posttest } \\
\text { Spring 1991 }\end{array}$ & $\begin{array}{c}\text { Winter } \\
1991-1992\end{array}$ & $\begin{array}{c}\text { Pretest/posttest } \\
\text { difference }\end{array}$ \\
\hline 1 & - & 92 & 102 & +10 \\
2 & 98 & 87 & 112 & +25 \\
3 & 72 & 86 & 101 & +15 \\
4 & - & $73^{\mathrm{a}}$ & $90^{\mathrm{a}}$ & +17 \\
5 & 86 & 86 & 97 & +11 \\
6 & - & Untestable & 79 \\
$M$ & 85.3 & 84.8 & 100.4 & +15.6 \\
SD & 10.6 & 6.3 & 10.9 & \\
SEM & \multicolumn{4}{|l}{} \\
\hline
\end{tabular}

Note. Pretests were administered in spring 1991. Dates of the posttest administration were between December 5, 1991 and January 13, 1992.

${ }^{a}$ Assessment was conducted with the Spanish-language version of the PPVT-R. 

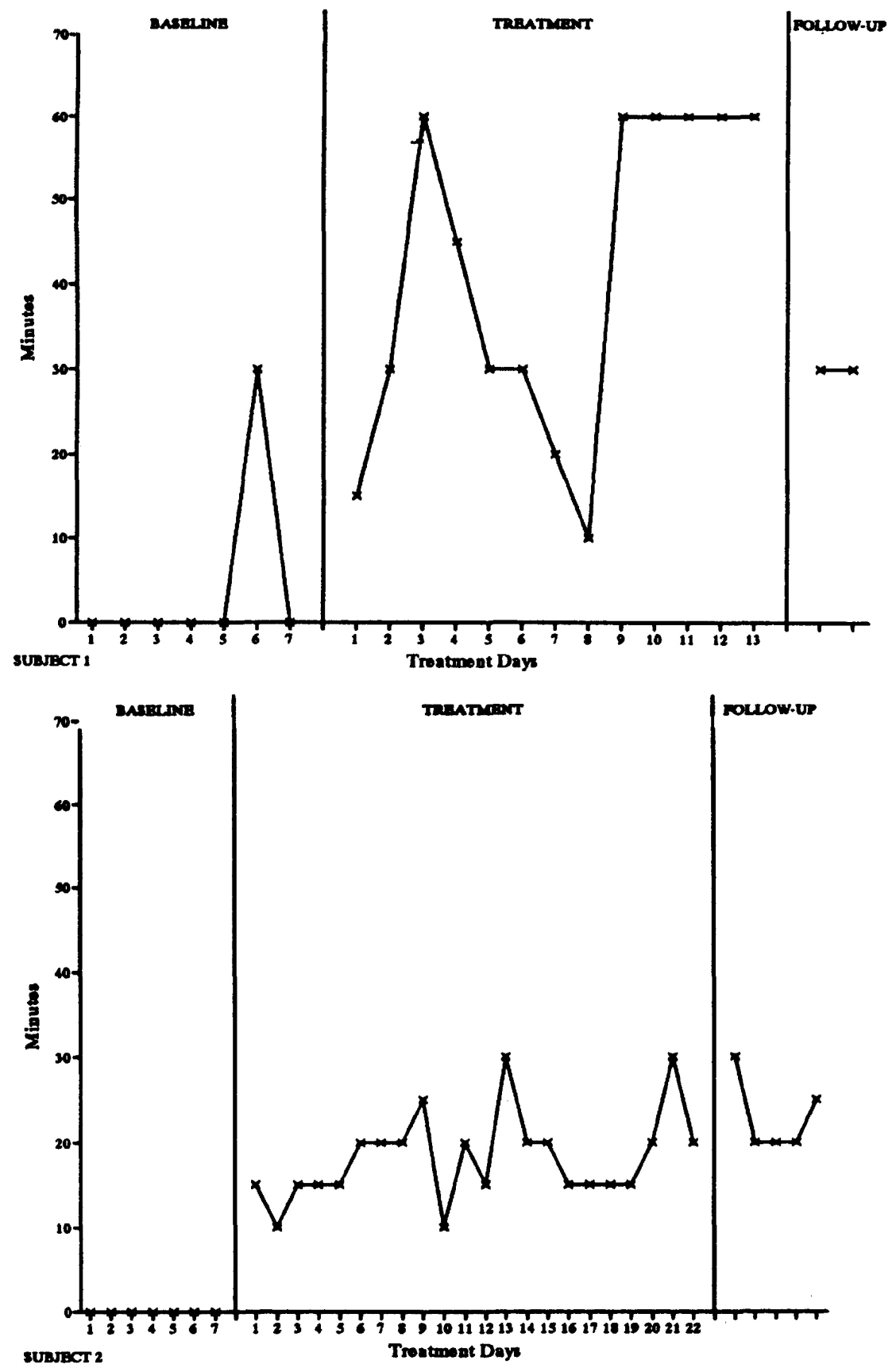

Figure 1. Behavioral data for frequency and duration of reading for 6 subjects across baseline, treatment and follow up conditions. 

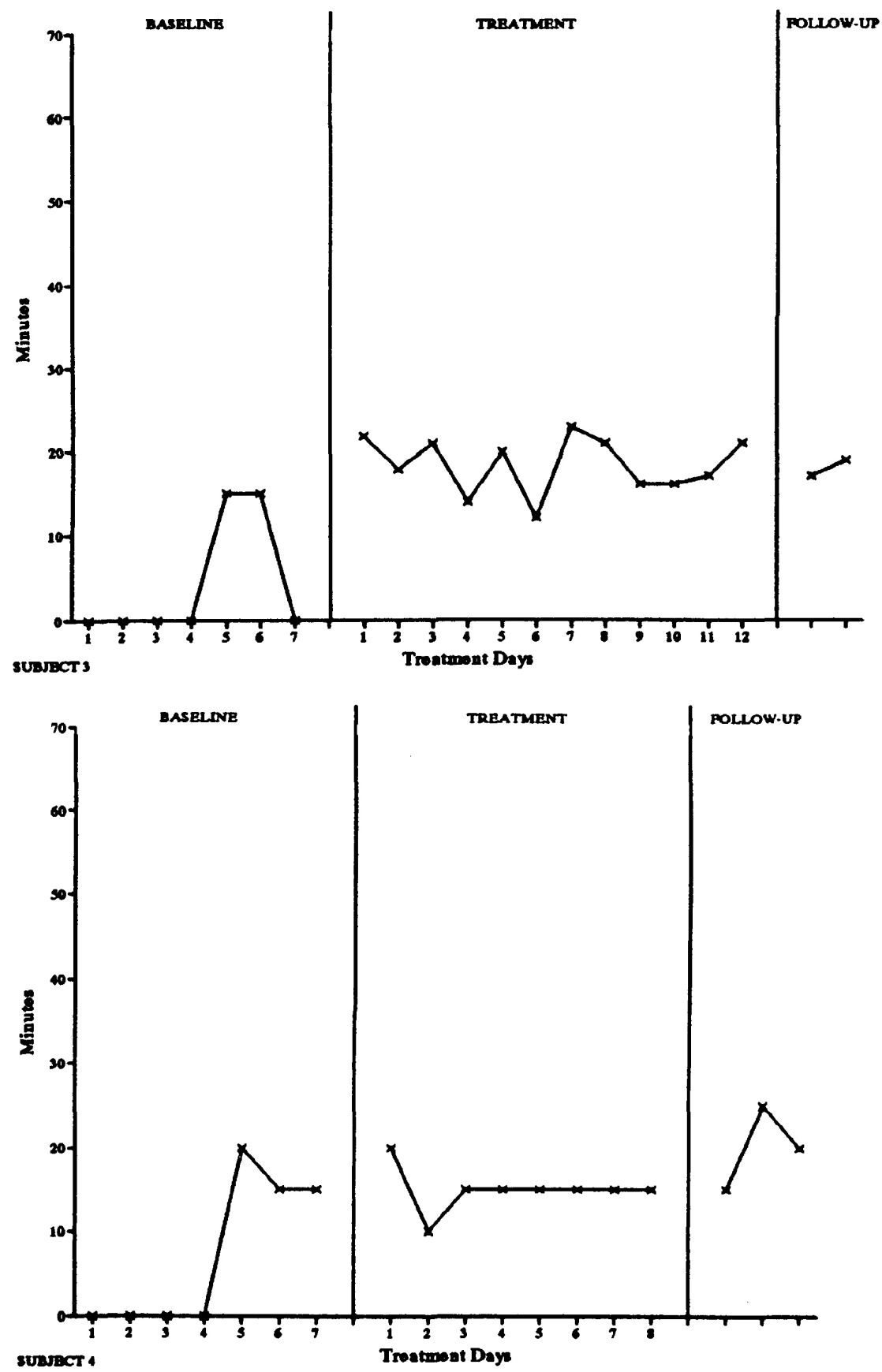

Figure 1. (continued) 

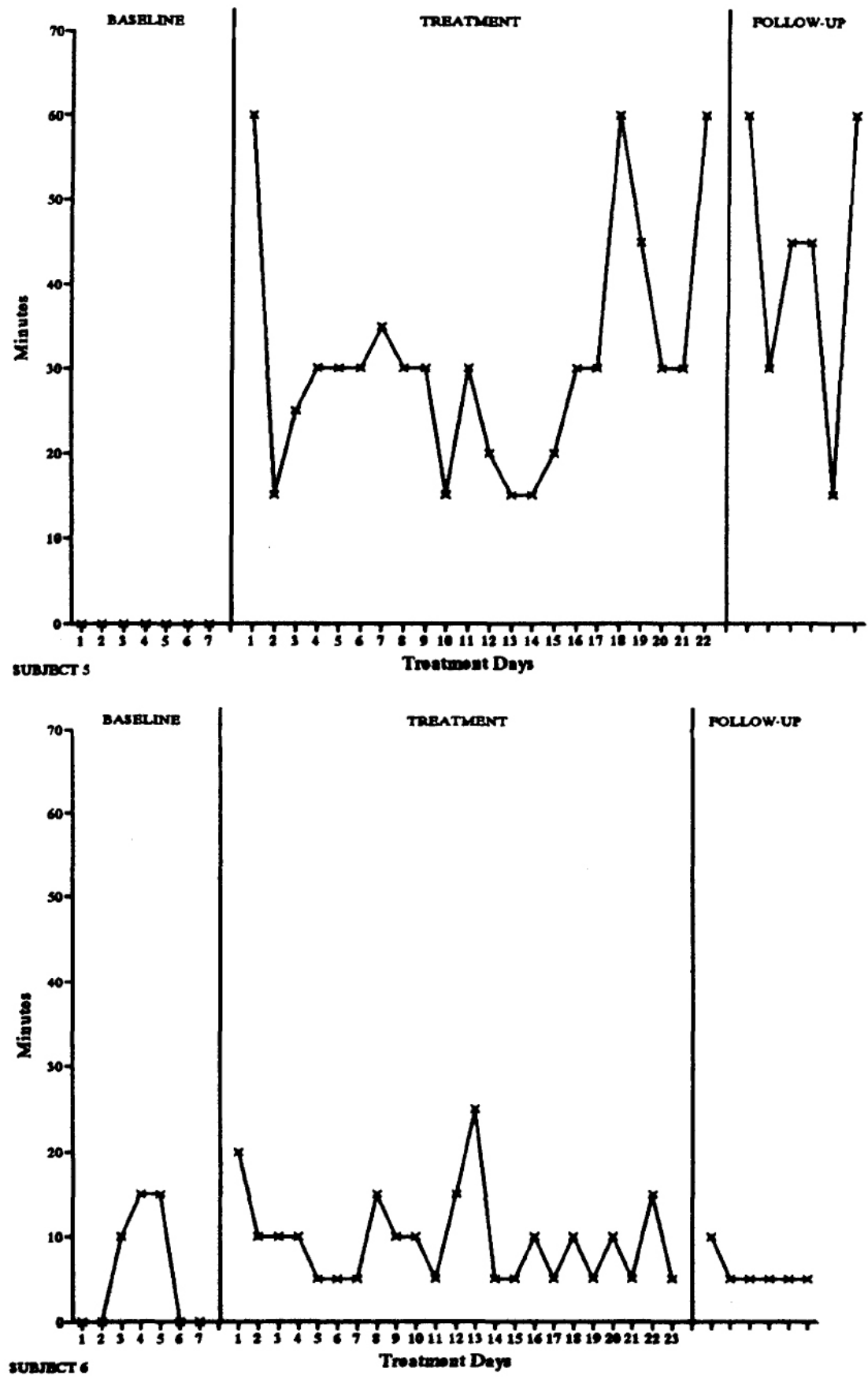

Figure 1. (continued) 
figure is essentially the same as the mean obtained for three children approximately six months earlier (85.3). Approximately six months later, after completion of parent-training, the average PPVT-R score obtained for the six subjects was 100.4 , with a range of 79 to 112 . The average gain during this period was 15.6 standard score points.

\section{Treatment Acceptability}

Parent responses on the BIRS indicated high levels of acceptability with the reading intervention. Out of a possible total 144 points, scores ranged from 118 to 131 , with a mean across subjects of 126 . Mean scores on the 24 items ranged from 6.0 (strongly agree) to 2.7 (slightly disagree), with a mean across items and across subjects of 5.2 (agree; $S D=.79$ ). Means for each factor of the BIRS were 5.21 for acceptability, 5.39 for effectiveness, and 4.75 for time to effectiveness.

The highest scoring items (all receiving scores of six from all parents) were: "This was an acceptable intervention for my child's need"; "I am willing to use this kind of intervention again at home"; "I liked the procedures used in the intervention"; and "Overall, the intervention was beneficial for us." The lowest scoring items included: "The intervention is consistent with others I have used at home" $(M=2.7, S D=1.7)$; and "My child's problem was severe enough to warrant the use of this intervention" $(M=3.3, S D=1.9)$.

\section{Treatment Integrity}

Across all subjects, parents reported completing between 67 and 100 percent of treatment objectives, with a mean of 90 percent. Objectives reported to have occurred with greatest frequency included "I arranged things so we found all needed materials"; "My child was cooperative during reading"; and "I used behavior management techniques discussed with the consultant." The objective reported as occurring with least frequency was "We read as much this week as last."

Analysis of the codes for interactive reading objectives provided an additional source of information about treatment integrity. During baseline, an average of two objectives were present (range $=0$ to $7, \mathrm{SD}=2.7$ ). Thus, 22 percent of targeted interactive reading behaviors were directly observed in subjects without treatment occurring. During the last week of treatment, 86 percent of interactive reading objectives were directly observed $(\mathrm{M}=7.7$; range $=6$ - 9; $\mathrm{SD}=1.3)$. At follow up, 69 percent of the interactive reading objectives were present $(\mathrm{M}=$ 6.2 ; range $=4-7 ; \mathrm{SD}=1.4$ ).

\section{DISCUSSION}

\section{General Findings}

This study demonstrated the use of a structured parent-training model for atrisk families. It followed recommendations for intervention research (Shapiro, 

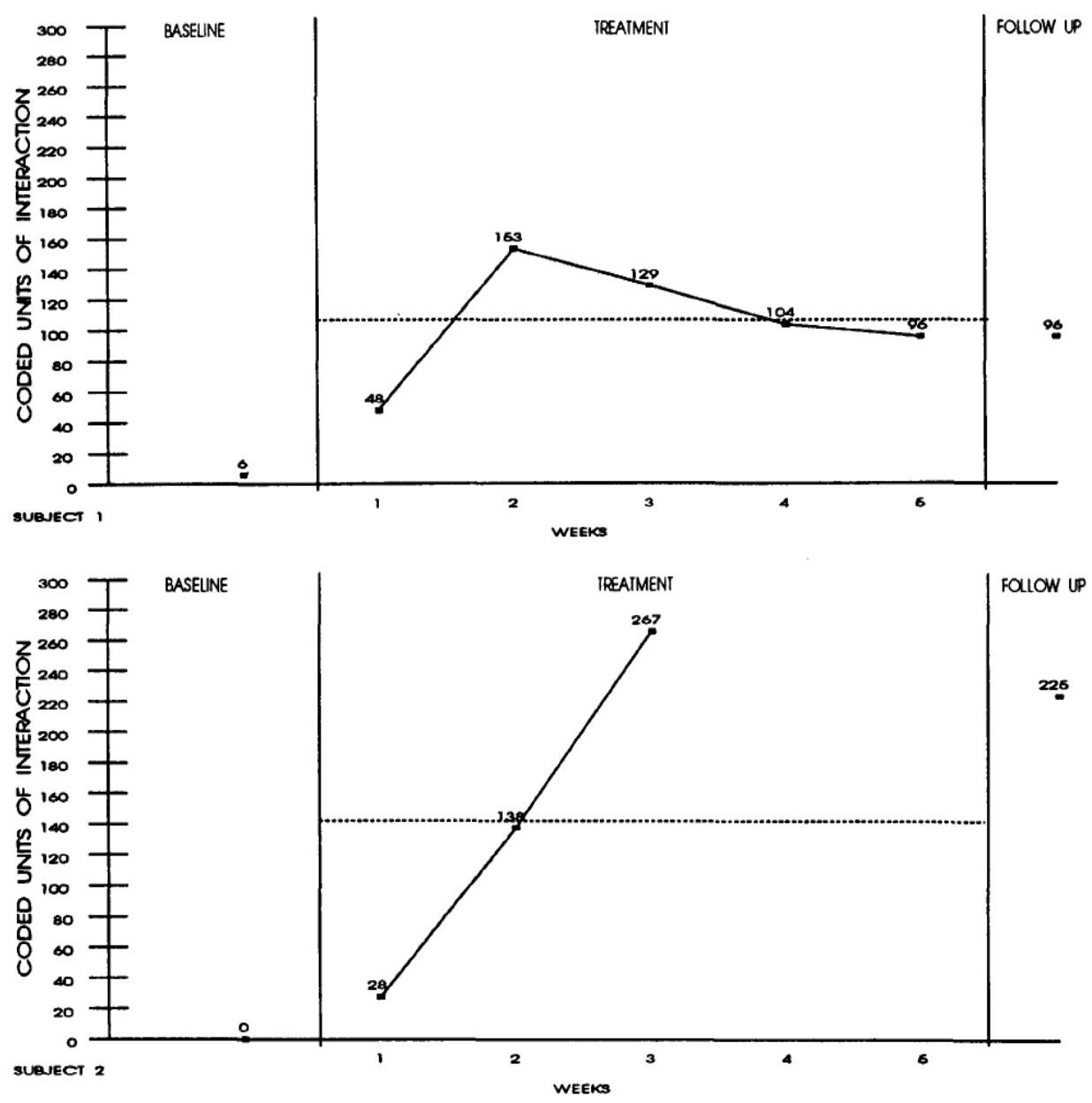

Figure 2. Behavioral data for number of reading objectives demonstrated by 6 subjects across baseline, treatment and follow up conditions.

1987) by including outcome measures for treatment acceptability and integrity of implementation. Likewise, the study design included a follow-up condition to determine maintenance effects.

During treatment, five of the six parents improved in regularity of interactive book reading occurring at home, as indicated by parent self-reports. Consistent with individual parent goals, number of days read per subject hovered around three per week. Likewise, inspection of Logs revealed a trend towards targeting a regular time and place for reading (i.e., establishing a pattern). Based on self- 

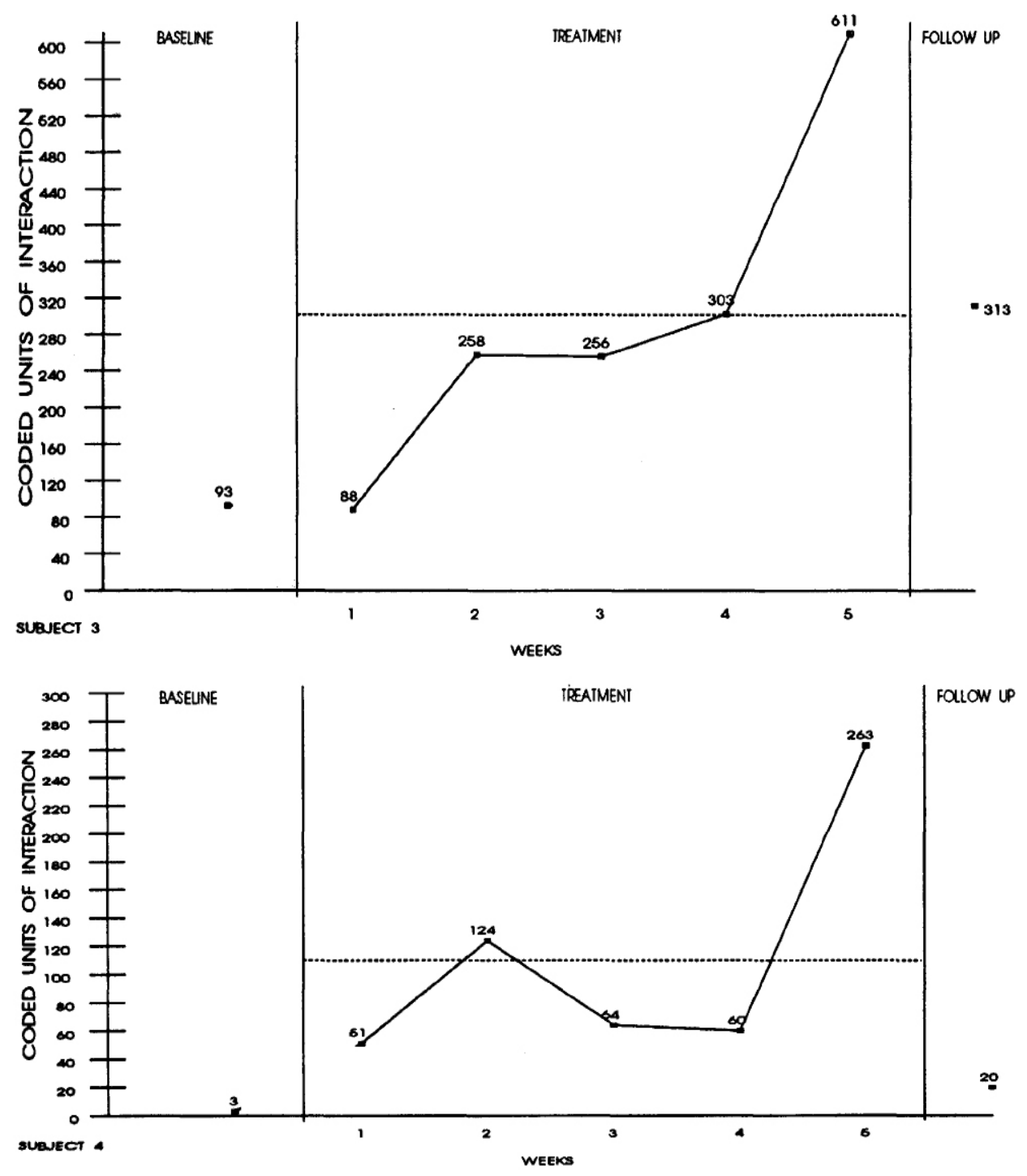

Figure 2. (continued)

report data, four subjects also demonstrated a statistically significant increase in the amount of time spent reading in treatment sessions. For four of six subjects, total minutes read per week increased immediately with the onset of treatment. Interactive book reading data indicate that the strategies were easily understood by subjects and readily implemented at home. Across all subjects, a strong im- 

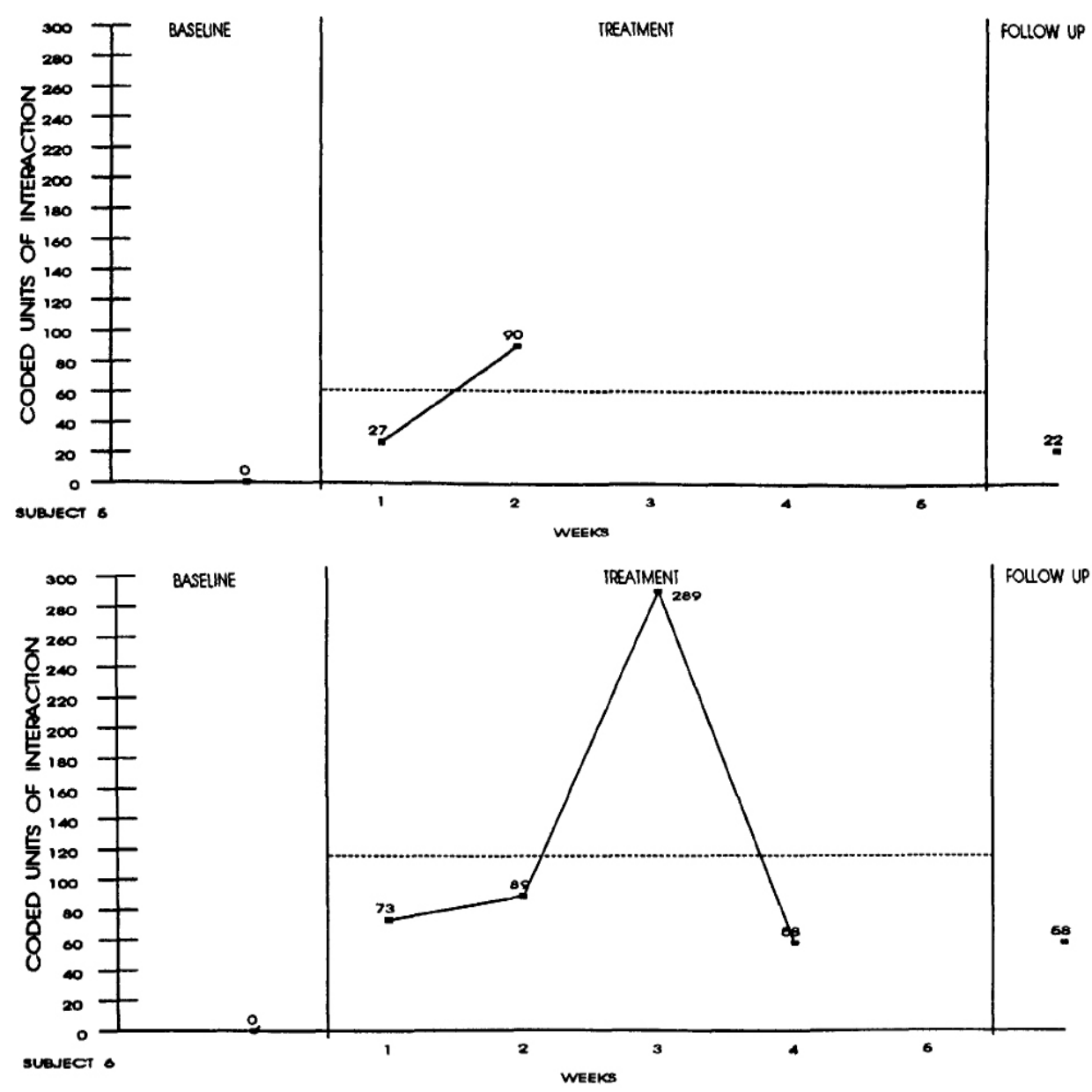

Figure 2. (continued)

mediacy effect with onset of treatment was noted, as demonstrated by the occurrence of codes in reading transcriptions.

Reading transcriptions demonstrated clear qualitative gains in responsive communication between parents and children during book reading. Before treatment, parents tended to start with the first line of text and read through the story, largely ignoring children's comments about the book. During treatment, the parents made use of the book to structure verbal interaction and exchange of ideas with their children. Based upon transcription statements, it appeared all dyads demonstrated 
improvement in maternal ability to structure a learning activity, including obtaining children's cooperation and sustained focus for the book at hand.

Approximately three months following intervention, gains in child subjects' PPVT-R scores ranged from 10 to 25 standard score points (average gain $=15.6$, $S D=10.9$ ). Five of the six subjects scored within the average range or better at follow up. Before treatment, only one subject (Subject 1) scored within the average range on this measure, and all other subjects scored in the below-average range or below. This is contrasted to no gains in PPVT-R scores between administrations six months prior to the study and at pretest for three subjects. A 10-point gain in IQ scores was commonly observed during the 1970s among at-risk children engaged in good intensive early intervention programs such as Head Start (Zigler \& Seitz, 1980). Sattler (1988) reported that minority children attending Head Start programs were observed to make average increases on the PPVT-R of up to 16 points. Results for the reading intervention mirrored such findings. The PPVT-R results reported here, however, are anecdotal and open to alternative interpretations (e.g., practice effects and regression toward the mean). It should be noted that the Even Start program in question was not an intensive intervention. Activities took place after school two days weekly for several hours.

\section{Study Limitations}

Although the study addressed important intervention components, a number of methodological limitations were evident, thus compromising the degree of confidence in the results. These include problems with design, data collection, and subject selection procedures.

Design. The present study originally proposed a multiple baseline across subjects design. Unfortunately, due to practical difficulties encountered with subject attrition and noncompliance with extended baselines, an AB with replication design was substituted. Although functional relationships between treatment and behavior cannot be demonstrated, this study employed some methodological strategies to increase inferences of treatment effects. These include the use of objective and continuous data collection procedures, replications across subjects, and replications under varied settings and times (Kazdin, 1992).

The AB with replication design is vulnerable to several threats to internal validity. The first threat is history. All target children were involved in school programs when follow-up assessment of receptive vocabulary was conducted. No attempt was made to control for the effects of other educational experiences concurrent to that of the experimental design, so the specific contribution of the interactive book reading intervention independent of other experiences (e.g., Even Start) is uncertain. A second threat to internal validity is the impact of repeated testing, history and maturation on the PPVT-R results. The test was administered up to three times with approximately six months between administrations, and the results are thus suspect. Third is a possible confounding of the effects of 
treatment and increased child maturity upon outcome measures. Given that the intervention was completed at a stage of development when children are naturally acquiring language, being exposed to books, and developing an ability to sustain attention for printed material, an alternative developmental explanation could be applied. The experimental control introduced in response to this threat was the strategy of multiple assessment occasions, across conditions, with objective data provided by the audiotaped reading sessions. (It should be recalled that the primary dependent variable in the study concerned parent behavior, which is less susceptible than child behavior to history and maturation, and not affected by pretest sensitivity.) A fourth uncontrolled threat to internal validity is potential subject reactivity in response to

(a) being informed they were participating in a research study and (b) using the tape recording and self-monitoring strategies during treatment and follow up. Gains might be explained by parents performing in a socially desirable manner. Relatedly, given the possible intrusiveness of the follow-up procedures (i.e., audiotapes and self-report logs), it is difficult to determine if subjects' behavior during the follow-up probe were similar to their natural behavior when "treatment-like" components were not in place.

Additional design limitations regard the lack of control or comparison groups and lack of reversal to baseline conditions. As suggested above, alternative explanations for children's increases in receptive language scores are possible (e.g., history, maturation). Likewise, subjects were enrolled in the Even Start program, and its instructional effects were not evaluated. A control group of child subjects matched on chronological age, ethnicity, primary language, estimated IQ, and exposure to Even Start instruction would assist in teasing out the specific effects of the interactive book reading intervention. Because no return to baseline condition was instituted, it is impossible to conclude that changes in subjects' behaviors were a function of experimental control. However, reversal designs may not be feasible when treatment involves skills training as in the present study.

Data Collection. Although the design called for continuous assessment, difficulties were encountered with data collection procedures. First, in three of the six cases (Subjects 2,5, and 6), there were no coded transcripts corresponding to the baseline condition (i.e., no reading occurred). This made comparative interpretations problematic. Second, single baseline data points are available for some dependent variables (i.e., days per week that reading took place; codable interactions during book reading), making comparisons between conditions difficult. Third, although the design included four outcome measures, two of these were parent self-reports, which lack objectivity. The technique of having parents record their own reading time is economical, nonintrusive, and convenient. However, the study included no reliability check to determine the accuracy of parent reports. Finally, the coding system for analyzing interactive book reading is experimental and its validity is uncertain. Other systems (e.g., Pellegrini, Perlmutter, Galda, \& Brody, 1990) may be explored as possible outcome measures and used to validate the present method. 
Subject Selection Procedures. The lack of clear criteria for subject selection presented a threat to external validity. Within the sample, subjects were characterized by an apparently significant range of linguistic and cultural backgrounds. Compared with the Even Start population of origin or with the educationally atrisk population at large, there was an overrepresentation of two types: (a) mothers of Spanish language background and (b) mothers residing in two-parent homes. Therefore, results may not be generalizable to other members of the subject class (e.g., Even Start mothers).

A main criterion for subject selection was parent interest and willingness to participate in the study. Likewise, because of the need to coordinate meeting times for several subjects and to adhere to timelines required by the experimental design, those households without telephones were eliminated from the subject pool. It is possible that individuals in the current study were those with a greater tolerance for risk taking, more upwardly mobile with respect to SES, or better established in their homes and neighborhoods.

\section{Implications for Practice}

This study contributes to an understanding of how parent-training may be of value to school professionals in their attempts to intervene proactively with underserved populations. It also provides an illustration of one manner in which school psychologists can foster parent support and home-school partnerships. As a strategy for interacting with educationally at-risk families, the professional activity associated with setting up home-reading practices offers a relatively nonthreatening terrain for parents unfamiliar with school settings. In the present study, reading books was found to be a useful point of contact with parents for beginning discussion about behavioral principles, communication strategies, and the need to establish routines for student achievement.

The intervention described here is appropriate for school-based practice with due consideration of the constraints upon staff and resources typical of urban public-school settings. At a time when funding for early-intervention programs falls short of the documented need, the intervention presents a promising approach to the problem of insufficient services to special needs families.

\section{Future Research}

A number of empirical issues remain in relation to this research program. First, experimental controls should be tightened to clarify findings of the current study. Future studies should address flaws of the current design including implementation of a multiple-baseline design and use of control and comparison groups. Likewise, components of the treatment (e.g., small-group training vs. individualized training sessions with parents) can be analyzed comparatively. Outcome measures should address the comparative effectiveness, acceptability, and social validity of intervention types for underserved populations. Possible research questions may include finding ways to improve the match between the 
intervention and subject characteristics. Comparative benefits in terms of maintenance of skills, costs of services, numbers of children helped, and teachers' responses to the intervention should be determined.

In conclusion, although empirical investigations are few, parent-training with at-risk parents appears to deserve the attention of service providers in publicschool settings. Findings of the current study suggest that relevant skills training can be an effective intervention at improving school skills among families at risk for chronic educational failure. Eventually, such undertakings may contribute to the development of needed service delivery models for the underserved groups making their place in communities and schools within the United States.

\section{REFERENCES}

Barkley, R. A. (1990). Attention-deficit hyperactivity disorder: A handbook for diagnosis and treatment. New York: Guilford.

Barona, A., Santos de Barona, M., Flores, A., \& Gutierrez, M. (1990). Critical issues in training school psychologists to serve minority school children. In A. Barona \& E. Garcia (Eds.), Children at risk: Poverty, minority status, and other issues in educational equity (pp. 187200). Silver Spring, MD: National Association of School Psychologists.

Becher, R. M. (1985). Parent involvement: A review of research and principles of successful practice. Urbana, IL: ERIC Clearinghouse on Elementary and Early Childhood Education. ERIC Document Number ED 247032.

Bernal, M. (1984). Consumer issues in parent training. In R. F. Dangel \& R. A. Polster (Eds.), Parent training: Foundations of research and practice (pp. 477-503). New York: Guilford.

Clark, R. M. (1988, Summer). Parents as providers of linguistic and social capital. Educational Horizons, 93-95.

Cooper, D. H., \& Speece, D. L. (1990). Maintaining at-risk children in regular education settings: Initial effects of individual differences and classroom environments. Exceptional Children, 57, 117-126.

Crosbie, J., \& Sharpley, C. F. (1991). DMITSA 2.0: A statistical program for analysing data from interrupted time-series. Author: Victoria, Australia.

Davis, W. E. (1991, August). Promoting effective communication between schools and parents of disadvantaged students. Paper presented at the annual meeting of the American Psychological Association, San Francisco, CA.

Dembo, M. H., Sweitzer, M., \& Lauritzen, P. (1985). An evaluation of group parent education: Behavioral, PET, and Adlerian programs. Review of Educational Research, 55, 155-200.

Duran, R. P. (1989). Assessment and instruction of at-risk Hispanic students. Exceptional Children, 56, 154-159.

Edwards, P. A. (1991). Strategies and techniques for establishing home-school partnerships with minority parents. In A. Barona \& E. E. Garcia (Eds.), Children at risk: Poverty, minority status, and other issues in educational equity (pp. 217-236). Washington, DC: National Association of School Psychologists.

Edwards, P. A., \& Panofsky, C. P. (1988). The effect of two training procedures on book-reading interactions of lower SES Headstart mothers and children. National Reading Conference Yearbook, 38, 135-143.

Fine, M. J. (1989). The second handbook on parent education: Contemporary perspectives. New York: Academic Press. 
Fine, M. J. (1990). Facilitating home-school relationships: A family-oriented approach to collaborative consultation. Journal of Educational and Psychological Consultation, 1, 169-187.

Forehand, R., \& McMahon, R. J. (1981). Helping the noncompliant child: A clinician's guide to parent training. New York: Guilford.

Fradd, S. H., \& Weismantel, M. J. (1989). Meeting the needs of culturally and linguistically different students: A handbook for educators. Boston: College Hill.

Hall, W. S. (1989). Reading comprehension. American Psychologist, 44, 157-161.

Harris, F. N., \& Jenson, W. R. (1985). Comparisons of multiple-baseline across persons designs and $\mathrm{AB}$ designs with replication: Issues and confusions. Behavioral Assessment, 7, $133-135$.

Huang, L. N. (1992, March). Elements of cultural competence. Paper presented at the 24th annual convention of the National Association of School Psychologists, Nashville, TN.

Huang, L. N., \& Gibbs, J. T. (1992). Partners or adversaries? Home-school collaboration across culture, race, and ethnicity. In S. L. Christenson \& J. C. Conoley (Eds.), Home-school collaboration: Enhancing children's academic and social competence (pp. 81-109). Silver Spring, MD: National Association of School Psychologists.

Kaufman, A., \& Kaufman, N. (1990). Manual for the Kaufman Brief Intelligence Test. Circle Pines, MN: American Guidance Service.

Kazdin, A. E. (1992). Research design in clinical psychology (2nd ed.). New York: Macmillan.

Kramer, J. J. (1990). Training parents as behavior change agents: Successes, failures, and suggestions for school psychologists. In T. B. Gutkin \& C. R. Reynolds (Eds.), The handbook of school psychology (2nd ed.) (pp. 683-702). New York: Wiley.

McMahon, R. J., \& Forehand, R. (1984). Parent training for the noncompliant child. In R. F. Dangel \& R. A. Polster (Eds.), Parent training: Foundations of research and practice (pp. 298-328). New York: Guilford.

Medway, F. J. (1989). Measuring the effectiveness of parent education. In M. J. Fine (Ed.), The second handbook on parent education: Contemporary perspectives (pp. 237-255). New York: Academic Press.

Morrow, L. (1983). Home and school correlations of early interest in literature. Journal of Educational Research, 76(4), 221-230.

Natriello, G., McDill, E. L., \& Pallas, A. M. (1990). Schooling disadvantaged children: Racing against catastrophe. New York: Teachers College Press.

Paget, K. D., \& Galant, K. (1991). Promoting communication competence in preschool-age children. In G. Stoner, M. R. Shinn, \& H. M. Walker (Eds.), Interventions for achievement and behavior problems (pp. 289-303). Silver Spring, MD: National Association of School Psychologists.

Passow, A. H. (1970). Deprivation and disadvantage: Nature and manifestations. In A. H. Passow (Ed.), Deprivation and disadvantage: Nature and manifestations (pp. 15-51). Hamburg, West Germany: UNESCO Institute for Education.

Pellegrini, J., Perlmutter, L., Galda, L., \& Brody, G. (1990). Joint reading between black Head Start children and their mothers. Child Development, 61, 443-453.

Rice, M. L. (1989). Children's language acquisition. American Psychologist, 44, 149-156.

Sattler, J. (1988). Assessment of children (3rd ed.). San Diego, CA: Jerome M. Sattler.

Shapiro, E. S. (1987). Intervention research methodology in school psychology. School Psychology Review, 16, 290-305.

Sheridan, S. M. (1993). Models for working with parents. In J. E. Zins, T. R. Kratochwill, \& S. N. Elliott (Eds.), Handbook of consultation services for children: Applications in educational and clinical settings (pp. 110-133). San Francisco: Jossey-Bass. 
Shields, P., \& Dupree, D. (1983). Influence of parent practices upon the reading achievement of good and poor readers. Journal of Negro Education, 52(4), 436-445.

Snow, C. (1983). Literacy and Language: Relationships during the preschool years. The Harvard Educational Review, 53(2), 165-187.

Sulzby, E. (1985, Summer). Children's emergent reading of favorite storybooks: A developmental study. Reading Research Quarterly, pp. 457-481.

Tawney, J. W., \& Gast, D. L. (1984). Single subject research in special education. Columbus, $\mathrm{OH}$ : Charles E. Merrill Publishing Co.

Teale, W. H., Hieber, E. H., \& Chittenden, E. A. (1987). Assessing young children's literacy development. Special issue: The state of assessment in reading. Reading Teacher, 40(8), $772-777$.

Teale, W. H., \& Sulzby, E. (1989). Emergent literacy: New perspectives. In D. Strickland \& L. M. Morrow (Eds.), Emerging literacy: Young children learn to read and write (pp. 1-15). Newark, DE: International Reading Association.

Tizard, J., Schofield, W. N., \& Hewison, J. (1982). Collaboration between teachers and parents in assisting children's reading. British Journal of Educational Psychology, 52, 1-15.

Von Brock, M. B., \& Elliott, S. N. (1987). Influence of treatment effectiveness information on the acceptability of classroom interventions. Journal of School Psychology, 25, 131-144.

Webster-Stratton, C. (1989). The parents and children series. Eugene, OR: Castalia Publishing Company.

Wehlage, G. G., Rutter, R. A., \& Turnbaugh, A. (1987). A program model for at-risk high school students. Educational Leadership, 70-73.

Welch, M. \& Sheridan, S. M. (1995). Educational partnerships: Sewing students at risk. San Antonio, TX: Harcourt Brace.

Wright Group (1990). A shared reading model: Just this once. Bothwell, WA: Wright Group.

Zigler, E., \& Seitz, V. (1980). Early childhood intervention programs: A reanalysis. School Psychology Review, 9, 354-368. 